\title{
¿Cómo los intelectuales conquistaron la moda? Discursos decimonónicos
}

Nathalie Goldwaser Yankelevich

Doutura, Universidad de Buenos Aires - / nathalie.goldwaser@gmail.com Orcid: https://orcid.org/0000-0002-8676-3409

Enviado 07/06/2018 / Aceptado 04/07/2018. 


\title{
¿Cómo los intelectuales conquistaron la moda? Discursos decimonónicos
}

\begin{abstract}
RESUMO
En este trabajo sostenemos que la noción "moda" y su retórica, obtuvo una forma conceptual similar a la de "intelectual": ambos conceptos fluyen en un vaivén entre el bien y el mal; lo banal o lo no superficial; entre la ideologización o politización y la desideologización o desaparición de su sentido sociohistórico, político y cultural. Así, trabajaremos sobre un dualismo (intelectuales - moda) que, relacionados por un interrogante, nos permitirá entender qué papel cumple un intelectual, y qué argumentos arroja cuando éste observa la moda. Asimismo, pretendemos demostrar que "las diferencias de los sexos" están permanentemente vinculadas con la temática en cuestión. Por ello, queremos exponer cómo el concepto 'moda' ha sido politizado durante el período en que se piensa "el progreso", la modernización o la modernidad (siglo XIX y principios del XX), tanto en Europa, como en el Río de la Plata (actual República Argentina).
\end{abstract}

Palavras-chave: Moda; intelligentsia; siglo XIX. 


\title{
How did intellectuals conquer fashion? Nineteenth-century discourses
}

\begin{abstract}
In this paper argue that the notion of "fashion" and his rhetoric, obtained a conceptual form similar to the one of "intellectual": two concepts flow into a back and forth between good and evil; the banal or the not superficial; among the ideologization, politicization and the deideologization or disappearance of their sense historical, political and cultural. Thus, work on a dualism (intellectuals fashion) as related by a question mark, will allow us to understand what role meets an intellectual, and arguments casts when this is fashion. In addition, we intend to demonstrate that "sexes differences" are permanently linked with the subject in question. Therefore, we want to expose how the 'fashion' concept has been politicized during the period in which thinks "progress", modernization or modern (19th-century and early 20th), both in Europe and in the Río de la Plata (current Republic Argentina).
\end{abstract}

Keywords: Fashion; intelligentsia; 19th century. 


\section{INTRODUCCIÓN}

Nuestras modas como se sabe no son, por lo común sino una modificación de las europeas, pero una modificación artística ejecutada por hombres inteligentes según el testimonio de los cuales vamos a presentar aquí las mas generales y nuevas entre los elegantes. (La Moda, 1837)

"Modas porteñas", en La Moda. Gacetín semanal de música, poesía, de literatura, de costumbres. ( $N^{\circ} 1$ Buenos Aires Noviembre 18 de 1837).

En este trabajo sostenemos que la noción "moda" y su retórica, obtuvo una forma conceptual similar a la concepción de "intelectual": ambos conceptos fluyen en un vaivén entre el bien y el mal; lo banal o lo no superficial; entre la ideologización o politización y la desideologización o, lo que es peor, la desaparición de su sentido sociohistórico, político y cultural.

Es así, entonces, que trabajaremos sobre un dualismo (intelectuales - moda) que, relacionados por un interrogante, nos permitirá entender qué papel cumple un intelectual, y qué argumentos arroja cuando éste observa la moda, en el sentido amplio que observaremos más adelante.

Para qué sirvieron los registros literarios sobre la indumentaria, el ornamento, las costumbres, los usos y hábitos $y$, por último, repensando aquella época, interrogarnos por la función (o defunción) de la moda en nuestros procesos de identificación.

Esta idea de "dualismo" la extraemos del apartado "La vida como dualismo" en Filosofía de la moda (de 1905), en donde Simmel nos advierte que en toda actividad -incluso la más fecunda o la que parezca que ha agotado toda su potencia-, hay algo que no ha podido llegar a plena exteriorización. Esto es debido a la mutua limitación que los elementos antagónicos se imponen.

Por ende, las apariencias nos permitirían sospechar de fuerzas más profundas, tensiones más contenidas, colisiones 
y paces de especie más dilatada que las patentes en el aspecto inmediato de la existencia. (SIMMEL, 2014 [1905], p. 31-32). Es por esta perspectiva, que nos aventuramos a realizar las siguientes reflexiones.

Por un lado, el desafío de articular el concepto de "intelectual" o intelligentsia con las concepciones sobre "la moda", y demostrar que las diferencias de los sexos están permanentemente vinculadas con la temática en cuestión. Por ello queremos exponer cómo el concepto 'moda' ha sido politizado durante el período en que se piensa "el progreso", la modernización o la modernidad (siglo XIX y principios del $X X)$, tanto en Europa, así como en una de las colonias de América en el Sur, el Río de la Plata (actual República Argentina). Esta propuesta pretende corroborar que, en Hispanoamérica, la inquietud decimonónica de los intelectuales por desembarazarse del colonialismo se encontraba en una disyuntiva: imitar o copiar las costumbres, las modas, los usos de la Europa no española, perder los rasgos autóctonos y originales; o ingresar y aceptar un mundo netamente criollo, mestizo o, en el peor de los casos, nativo y salvaje. Contradicción y tensión planteadas por algunos de los hombres de la llamada "juventud romántica argentina" o Generación del 37, que nos permiten proceder a la inversa de algunas posturas que consideran únicamente que es la novedad, lo nuevo o la moda europea la que conquistó Hispanoamérica.

Tal como aseveró Alberdi en "Carácter histórico del Derecho Constitucional Suramericano: su división esencial en dos períodos diferentes" ${ }^{11}$ :

Todo el derecho constitucional de la América antes española es incompleto y vicioso, en cuanto a los medios que deben llevarla a sus grandes destinos. (...) Ninguna de las constituciones de Sudamérica merece ser tomada por modelo de imitación, por los motivos de

${ }^{1}$ Capítulo Segundo perteneciente a Bases y puntos de partida para la organización política de la República Argentina, derivados de la ley que preside al desarrollo de la civilización en la América del Sur, cuya primera edición es en Valparaíso, mayo de 1852. En adelante, Bases. 
los que paso a ocuparme. (...) Todas las constituciones del último período son reminiscencia, tradición, reforma muchas veces textual de las constituciones dadas en el período anterior. (ALBERDI, 1981 [1852], p. 69-70).

Afirmamos que son los sujetos, socialmente insertados en un estilo de vida, como lo fue el romanticismo -en tanto tendencia cultural-, los que conquistaron y exaltaron la propia personalidad en busca de la expresión libre, un culto al "yo" para diferenciarse de lo general. "Sólo si se tienen en cuenta las exageraciones en la moda romántica y la necesidad de subrayar nuevamente lo hispánico es posible entender la moda (...)" que domina el período desde 1830 (SAULQUIN, 1990, p. 38-39).

Por adelantar un segundo ejemplo del corpus decimonónico, Esteban Echeverría, padre fundador de la elite intelectual del 37, pensador y poeta, con cuyo nombre se asocia el comienzo del americanismo intelectual y literario en el Río de la Plata formula que: "Pediremos luces a la inteligencia europea, pero con ciertas condiciones. (...) tendremos siempre un ojo clavado en el progreso de las naciones, y otro en las entrañas de nuestra sociedad ${ }^{2 \prime}$ (ECHEVERRÍA, 1838, en ALTAMIRANO, 2005, p. 17).

\section{El arte de comparar los conceptos ¿De la intelligentsia o el intelectual?}

Los nombres de Fortoul, de Leroux, Bernager, de Quinet, de Massini, significan el arte moderno y el progreso del mundo (La Moda y la justicia).

"Literatura", en La Moda. Gacetín semanal de música, poesía, de literatura, de costumbres. ( $\mathrm{N}^{\circ} 2$ - Buenos Aires Noviembre 25 de 1837)

El término intelligentsia fue empleado por primera vez en Rusia en el siglo XIX: los que habían pasado por las universidades y recibieron una cultura, en lo esencial de origen occidental, constituían un grupo poco numeroso, exterior a los cuadros tradicionales. Se reclutaban entre los

\footnotetext{
2 Texto extraído del Dogma Socialista, obras escogidas. Caracas: Biblioteca Ayacucho, 1991, $253-253$.
} 
"segundones de las familias aristocráticas", los hijos de la pequeña burguesía, o incluso de campesinos acomodados; desligados de la antigua sociedad, se sentían unidos por los conocimientos adquiridos y por la actitud que adoptaban respecto al orden establecido. El espíritu científico y las ideas liberales contribuían igualmente a inclinarse hacia la revolución. La intelligentsia se sentía aislada, hostil a la herencia nacional y acorralada en la violencia. (ARON, 1967 [1955], p. 205) ${ }^{3}$. En este sentido, entendemos que -en sus inicios- el uso del mote "intelligentsia" era del orden de lo peyorativo.

En el Diccionario Enciclopédico Ilustrado de la Lengua Española, publicado bajo la dirección de José ALEMANY Y BOLUFER del año 1945, no figura la palabra intelligentsia, pero se encuentra desde luego "intelectual": "adj. Perteneciente al entendimiento // Espiritual o sin cuerpo // Dedicado al cultivo de las ciencias y letras". La misma definición aparece en la página web de la Real Academia Española en 2018, y aclaran que deriva del latín intellectuālis $^{4}$. Nada se dice de su origen ni de su rol político.

Por el contrario, en el Trésor de la Langue Française informatisé [Tesoro de la Lengua Francesa Informatizada], aparece la entrada "Intelligentsia, intelligentzia", como sustantivo femenino. Allí también se la asocia históricamente al siglo XIX de la Rusia Zarista. Se la concibió como la vanguardia intelectual que militaba por reformas políticosociales. En resumen, este término de origen ruso tiene en su historia -y en su definición- mayor politización que el término hispano "intelectuales". Es por ello que aquí usaremos indistintamente uno y el otro, precisamente para darle el cariz político al papel del intelectual.

\footnotetext{
${ }^{3} \mathrm{Cfr}$. también con BAÑA, 2014, "Apogeo y declive de la intelligentsia rusa. Entre el trabajo intelectual y el deber moral", en http://nuso.org , Septiembre - Octubre. Acceso libre [consultado abril 2018].

${ }^{4}$ Cfr. http://dle.rae.es/?id=Lqb2TD7 [consultado Abril 2018].
} 
Agregamos entonces sobre la intelligentsia, que éstos pueden ser poetas, ensayistas, estudiosos, escritores, políticos, artistas, científicos, profesores, autodidactas o periodistas. De modo que preferimos vincular a esta figura, con el análisis y realización de un diagnóstico. El intelectual traduce, es un puente (o debería serlo) entre la sociedad civil, la ciudadanía, el Estado y el conocimiento adquirido, científico o no. ROMANO SUED (2016) señala que la tarea ardua del intelectual consiste en escribir y volver a pensar significados, acontecimientos y objetos dentro de movimientos y sistemas más amplios, ya que hay un enlace de relaciones múltiples entre mundos textos y lenguas que se revelan una y otra vez de manera tensa y contradictoria.

El intelectual pregona porque comprende y explica, siempre bajo su subjetividad, su posicionamiento político e ideológico, sus creencias y sus perspectivas. Sin embargo, no es frecuente en la actualidad ligar a la intelligentsia con cuestiones de moda o de modas políticas. Ni en la vida pública ni en la vida privada contemporánea pueden encontrarse asociaciones, salvo escasas excepciones.

Pero en el siglo XIX, hubo varias personalidades -que se consideraban intelectuales- vinculadas explícitamente a la temática acerca de la moda, no sólo en Europa, sino también en América en el Sur, en particular, en el Río de la Plata.

Para finalizar, somos conscientes de las divergencias en los procesos y contextos históricos de cada territorio en donde escriben los intelectuales que vamos a analizar aquí (Europa e Hispanoamérica).

Nos apoyamos, para el primer caso, en lo que Gisèle SAPIRO (2017) resume en "El espacio intelectual en Europa entre los siglos XIX y XX": El proceso de formación de los Estados-nación contribuyó a la desintegración de la comunidad letrada europea, que se comunicaba en una sola lengua, el latín. Con las lenguas vernáculas, el nacimiento del mercado del libro y la expansión del público lector a 
grupos sociales, no necesariamente formados en las humanidades clásicas -mujeres, clases medias urbanas, y luego la clase obrera-, la fragmentación fue un hecho. Si el francés fue -hasta el siglo XVIII- la lengua de la cultura de las cortes europeas; la Kultur alemana se impuso con su austero rigor frente al encanto superficial de la civilisation francesa, iniciando el proceso de nacionalización de la cultura letrada. Por su parte, la traducción se convirtió en el principal modo de circulación trasnacional de textos.

Todo ello conllevó al desarrollo y la diferenciación de las profesiones intelectuales que tomaron formas variables de acuerdo a las estructuras políticas y administrativas de los distintos países y a las relaciones de competencia entre sí.

En razón del papel central otorgado a la cultura, la
construcción de identidades nacionales dependió muy
especialmente de los productores de representaciones
colectivas que eran los intelectuales. Hombres de
letras, publicistas y pensadores del mundo social,
proclamadores de un futuro radiante o nostálgicos de
un pasado perdido, asumieron el rol de profetas del
mundo moderno. Esta construcción nacional se
desarrolló en el marco de una competencia
internacional cada vez más intensa que tuvo a Europa
como su centro, y se constituyó en un modelo que
circuló de un país a otro a través de un proceso
mimético. (SAPIRO, 2017 , p. 26; cursivas nuestras).

Para el caso Hispanoamericano, entendemos que ante la "disolución del orden colonial y la construcción del primer orden independiente" (ANSALDI, GIORDANO, 2012, p.159), se dieron diversos factores que van de la insurrección a la permanencia de lealtades. Se aíslan algunos escenarios acaecidos, pero nos interesa aquel en que, al desplomarse la legitimidad del virreinato, la competencia por el estatus entre elites criollas insurgentes -por no tener acceso a los cargos públicos-, se torna, específicamente en el caso rioplatense, en competencia por detentar el poder público.

América Latina es vista como "la familia" histórica de la que se forma parte, y como sinónimo de las adversidades de 
las que se busca escapar para ingresar en la ruta de la civilización.

[L]a observancia general de Claudio Lomnitz se aplica enteramente a la Argentina: 'En América Latina la problemática identitaria surge como parte de la obsesión nacional por explicar y remediar el atraso, ante el fracaso de las independencias y de la soberanía nacional como mecanismo civilizatorio'. (ALTAMIRANO, 2005, p. 106-107).

Para Altamirano, la opción que adoptó "la minoría" fue la de transformar la fisonomía nacional, además de redefinir las relaciones con el resto de América del Sur, esto implica que estar geográficamente en América Latina no significaría, siempre para los argentinos, identificarse como latinoamericanos.

Para completar esta silueta escénica, en donde escribían los rioplatenses, hijos de la Revolución independentista, se debe advertir que:

La noción comunitaria de nación es problemática en el Río de la Plata y en toda América, porque los actores del levantamiento eran criollos, y los fundamentos de su identidad consistían justamente en su pertenencia a la cultura metropolitana [...] El problema en el Río de la Plata radica precisamente en que el pacto fundador de la comunidad política no logra tomar forma, antes de la redacción de la Constitución de la Confederación Argentina en 1853, que proclama la unión nacional. (BERNARLDO de QUIRÓS, 2008, p.31).

Sin embargo, no se deja de "pretextar la nación", se la invocaba durante las reuniones de intelectuales en las sociedades literarias, una nación que evocaban tanto una denuncia de una "horda" que venía a sustituir al pueblo; como una que debía civilizar la barbarie.

\subsection{De la moda}

[A] veces la moda se asemeja a estas coquetas jovencitas que después de haber agotado las novedades del gusto se ponen a imitar a las señoras viejas, por un refinamiento de coquetería. La edad media es la vieja que arremeda la moda del día. 
"Ultimas modas francesas", en La Moda. Gacetín semanal de música, poesía, de literatura, de costumbres. ( $\mathrm{N}^{\circ} 1$ - Buenos Aires Noviembre 18 de 1837).

Para definir "la moda" debemos considerar que, en tanto concepto inherente a la noción de cultura material, y categorías asociadas tales como vestimenta, ornamentos, costumbres, tradiciones y hábitos -estas tres últimas son el alter ego a "la moda"-, ella ha suscitado un creciente interés en distintos campos disciplinares. Se debe, en parte, a que la moda impone condiciones no sólo de universalización, sino de particularización (BENJAMIN, 2016, p. 93 y ss.) ya que su tiranía incluye el imperativo que no se la adopte de manera automática, esto es, que no se la copie. Cabe destacar, dentro de la obra inconclusa y enigmática de Walter BENJAMIN, Libro de los Pasajes, en "Apuntes y Materiales. B [Moda]", escrito entre 1927 y el año de su muerte $(1940)^{5}$, algunas definiciones, como éstas, que nos serán útiles para comprender la historia material del siglo XIX europeo.

Por moda entenderemos no sólo los efectos producto del vestir, sino además una práctica ligada a la incorporación de lo novedoso, las nuevas tendencias en materia política, jurídica/legislativa, literaria, económica, social, artística y cultural.

Las costumbres se vinculan a una repetición rutinaria de una eterna imitación conservadora. La moda es también una imitación, pero inesperada, que se enlaza con el pasado, con el presente y con el porvenir. Esta imitación es fundamental -escribió SIMMEL (2014 [1905], p. 34 y 35)- tanto para el individuo, para el científico como para la moda. En el

\footnotetext{
5 Agradezco al Dr. Francisco Naishtat su intercambio sobre este fragmento: "pertenece a la composición del Passagen-Werk (Libro de Los Pasajes). Ahora bien, este libro se editó póstumamente recién en 1982, como volumen V de las obras completas (Gesammelte Schriften), editadas por Tiedemann y Schweppenhäuser, bajo supervisión de Adorno y de Scholem". Sobre la exactitud de escritura de ese fragmento es, precisamente, incierto o casi imposible de saber. "Lo que podemos decir es que Benjamin trabajó en el manuscrito y en la investigación del Libro de los Pasajes entre 1927 y 1940, es decir, durante trece años. Ese fragmento sobre la moda fue redactado durante ese intervalo. No te podría decir mucho más, si no es que por los temas, figuras, nombres daría la impresión de que corresponde a la segunda fase de la investigación de los Pasajes, la cual se inició cuando Benjamin se exilió definitivamente en París, a partir de la primavera boreal de 1933, inmediatamente después del ascenso de Hitler al poder en Alemania".
} 
individuo, engendra en el orden práctico la misma peculiar tranquilidad que goza para el científico cuando hemos subsumido un fenómeno bajo un concepto genérico; la moda, en tanto fenómeno constante en la historia de nuestra especie, sus condiciones vitales quedan circunscriptas a una imitación de un modelo dado, y satisface así la necesidad de apoyarse en la sociedad, conduce al individuo. Pero, a diferencia de las costumbres y hábitos, la moda tiene dos funciones radicales: unir y diferenciar, y esto implica dejar excluido a un círculo que no la puede seguir. Es la "oclusión hermética" de la moda. (SIMMEL, 2014 [1905], p. 37 y p. 52).

El papel de la moda, entonces, se da en una combinación entre lo que se deja y se retoma del pasado, las exigencias del presente y su indefectible transformación futura:

De manera diacrónica, se considera el concepto modernus, cuyo étimo, modus, se lo relaciona con la moda, en su derivación del adverbio temporal 'modo' que lleva implícita la idea de novedad, y el reconocimiento del derecho de toda época, generación o cultura a afirmar cierto grado de progreso respecto a lo antiquus (GODOY DOMÍNGUEZ, 2008); para Baudelaire, como veremos más adelante, era lo transitorio, lo fugaz, lo contingente. (BAUDELAIRE, 2013 [1863]).

En su aparición sincrónica, revela también las condiciones de los sexos en sus diferentes esferas porque los atributos del vestir, la elegancia y el buen gusto están relacionados con el proceso social y político que instaló la idea de civilización en el occidente moderno ${ }^{6}$.

Por poner un ejemplo de lo diacrónico y sincrónico simultáneamente, la idea de nación -una forma moderna de identidad colectiva que supone límites y determinaciones- no se explica por sí misma, sino que se debe buscar sus condiciones de emergencia y durabilidad. Consideramos que

${ }^{6}$ Cfr. Goldgel, 2013, p. 111 y ss.; Zambrini, 2009; Simmel, 2014 [1905], p. 32 
las configuraciones de las relaciones entre los sexos explicarían un aspecto de esa historia. Estas pueden observarse a través de los documentos históricos de intelectuales que aluden a la moda.

Por ello es que nos interrogamos: ¿cómo ha sido vista las diferencias sexuales, en tanto fenómeno indeterminado, y qué rol cumplió la moda en esas configuraciones? ¿Por qué y qué motivó a la élite intelectual y política a mencionar a la moda y a los sexos en su unión o en su diferenciación hombre/mujer?

Aquí [se refiere a la segunda mitad del siglo XIX] la moda ha inaugurado el lugar de intercambio dialéctico entre la mujer y la mercancía -entre el placer y el cadáver- (...) Pues nunca fue la moda sino la parodia del cadáver multiforme, provocación de la muerte mediante la mujer, amargo diálogo en susurros, entre risas estridentes y aprendidas, con la descomposición. Eso es la moda. Por eso cambia con tanta rapidez (...) y ya es de nuevo otra para cuando la muerte intenta golpearla. (BENJAMIN, 2016, p. 92 [B 1,4])

El mundo del siglo XIX comenzaba a modernizarse, hubo un desencantamiento o desmagificación de las imágenes del mundo (sic Max WEBER, 1917-1919) y cada esfera de valor tuvo su posición frente a la moda:

a) Esfera jurídica, por ejemplo, a través de las leyes suntuarias se impedía formalmente que las personas, no pertenecientes a la aristocracia, pudieran emular una mejor pertenencia social mediante la vestimenta. El período de normatividad más significativo fue en la baja Edad Media y comienzos de la Edad Moderna. (ZAMBRINI, 2009).

b) Esfera religiosa porque se condenaba el uso de ciertos tipos de prendas y atuendos para las mujeres y para los hombres por miedo a la confusión entre los sexos, principalmente miedo al travestismo, una figura contrapuesta a la familia;

c) Esfera erótica porque la moda era, por ejemplo, un medio por el cual la mujer podía resaltar su figura $y$ 
mostrarle al hombre su imagen más seductora, la promesa más íntima de su figura (BENJAMIN, 2016: 92 [B 1, 8]);

d) Esfera económica, asociada al florecimiento de la moda y de la prensa de moda (a través de la producción y venta de ciertas prendas de vestir y adornos que, según las costumbres de cada época, se diferenciaban o se igualaban);

d) Y con ello también aparecería, en la esfera de la política, la materialización de la noción de "libertad" en el vestir, como emergente filosófico y político, por ejemplo, del republicanismo y del liberalismo (el gorro frigio, por poner un ejemplo de indumentaria) (BARD, 2012).

Entonces, para construir una historia más exhaustiva de la cultura material, las investigaciones deben basarse en los archivos si se pretende hacer una reconstrucción más acabada de la historia de la cultura, la política y la identidad. En ese sentido, el concepto moda es un catalizador que se adelantaría a las reacciones políticas, sociales y culturales. "El más ardiente interés de la moda reside para el filósofo [el intelectual] en sus extraordinarias anticipaciones" (BENJAMIN, 2016, p. 93).

Se la intentó banalizar, vaciar de contenido o reducir a un aspecto, el de las ciencias aplicadas (particularmente al diseño textil e indumentaria). Pero la moda nos ofrece giros insospechados, porque ella es una herramienta potenciadora de las diferencias, exacerba contrastes aumentando tanto las divergencias biológicas y naturales como ideológicas, y ofrece un modo de comportamiento acorde al orden existente (BARD, 2012, p. 14);

Otras veces, fue un medio para realizar proclamas en pos de la igualdad, la libertad o para denunciar las violencias y el caos.

\section{ARTICULACIONES I: INTELECTUALES EUROPEOS Y LA MENCIÓN A LA MODA}


La moda, participa entre nosotros de la indecisión que afecta todas nuestras cosas sociales. No tenemos modas dominantes, como no tenemos ideas, ni costumbres dominantes. Entre tanto, es menester caminar a la homogeneidad.

"Modas de Señoras", en La Moda. Gacetín semanal de música, poesía, de literatura, de costumbres. ( $N^{\circ} 3$ Buenos Aires Diciembre 2 de 1837).

Desde el siglo XVI tanto en Italia como en Francia se descubren nuevos modos de vestir a través del personaje Pantaleón en la commedia dell'arte en el que dicho personaje representa un anciano rico y avaro con un traje específico -calzoncillos largos que luego devienen en la prenda pantalón (BARD, 2012, p. 11).

En Inglaterra, por su parte, aparecerá la obra Utopía de Tomás Moro en 1516, una parábola o alegoría en el que se critica la vida y las costumbres inglesas ${ }^{7}$. Para ello utilizará la indumentaria y el ornamento para reprochar aquella sociedad:

Con más vanidad que prudencia determinaron presentarse [los Embajadores ingleses a la isla de Utopía] y herir los ojos de los miserables utopianos con el esplendor de su vestimenta (...) Todos iban vestidos de los más diversos colores, de seda en su mayor parte. (MORO, 2008 [1516], p. 40).

A su vez, hacer una proclama por una sociedad nueva basada en la igualdad, que se encuentra en principio en la Isla Utopía, un no-lugar. Escribe Moro: "Todos han de llevar el vestido del mismo color, un color propio de ellos". (MORO, 2008 [1516], p. 40).

Sin embargo, en este apartado trabajaremos sobre un pequeño recorte de autores europeos que han sido testigos ya de las transformaciones revolucionarias del continente, y por ende, son partícipes de un nuevo espacio público en el que se da el proceso de modernización, tales como Honoré de Balzac (quien en 1830 publica el Tratado de la vida

${ }^{7}$ Cfr. GOLDWASER YANKELEVICH, 2008. 
elegante por primera vez en el semanario La Mode, creado en 1829 y dirigido por Émile de Girardin, uno de los pioneros del periodismo francés moderno); Charles Baudelaire en El pintor de la vida moderna. Lo bello, la moda y la felicidad, publicado en 1863 en el periódico francés Le Figaro; y, como anticipamos, un autor de fines del siglo XIX y principios del $X X$, George Simmel con sus textos originariamente en lengua germana, Filosofía de la moda de 1905 y Digresión sobre el adorno de 1908.

Balzac, un exponente intelectual que supo recuperar en sus escritos y aforismos, de manera irónica y sarcástica, el papel de la moda, arroja una definición enteramente relacionada con la idea de nación. Allí reveló una "patología de la vida social" propia de la modernidad europea. Se interrogó por los hábitos y costumbres que hacen a la distinción entre personas que gozan de la fortuna, en detrimento del pueblo; describiendo a la moda como lo que envilece o muere al volverse común pero que existe $y$ estipula nuevas modas gracias al poder de la opinión. El hombre que viste a la moda, no sólo es un moderno, sino que depende de aquel hombre que no puede portarla, el trabajador. Lo escribe sin tapujos: la moda sólo emerge en un pueblo de pobres y en una nación de personas que producen y personas que consumen. (BALZAC, 2013 [1830], p. 11). Benjamin aportará lo suyo al decir que: "El lema de Balzac es sumamente apropiado para explicar (...) que esta época no quiere saber nada de la muerte, que la moda también se burla de ella" (BENJAMIN, 2016: 95).

En Balzac se apoya Charles Baudelaire. En El pintor de la vida moderna. Lo bello, la moda y la felicidad desplegará los elementos que permiten descifrar las costumbres, la moral y la estética de una época lo cual implica lo eterno y lo relativo. Mientras que lo eterno lo descarta por no permitir una identificación clara y determinada de un tiempo 
histórico; lo relativo, que implica la moda, la moral y la pasión, permite comprender ese contexto.

En el apartado IV "La modernidad" asevera que:

Sin duda, tal como lo he retratado, este hombre [se refiere al dandy o al alma del autor o al artista, aunque este último es el que menos le conforma como denominación], este solitario de imaginación activa, siempre en marcha por el gran desierto de hombres, tiene un objetivo mas elevado (...) distinto del placer fugaz de la circunstancia. Busca lo que se me permitirá llamar la modernidad (...). Se trata, en su caso, de rescatar de lo histórico cuanto la moda contenga de poético, de extraer de lo eterno de lo transitorio. (BAUDELAIRE, 2014 [1863], p. 21; cursivas en el original).

Se referirá al arte moderno, en particular a los cuadros que visten a sus personajes con trajes antiguos, que recurren a modas y ornamentos del Renacimiento, y los tilda porque los pintores de su propia actualidad (siglo XIX), pudiendo elegir temas "generales y adaptables a todas las épocas", se obstinan por cubrirlos con "mamarrachos de la Edad Media, el Renacimiento o el Oriente". Una clara proclama por la modernización y por la incorporación de lo nuevo en lo viejo.

Para terminar este condensado recorrido por ciertos intelectuales europeos que han referido sobre la moda, revisitamos a quien, apenas comenzado el siglo XX, escribirá una filosofía de la moda: Georg Simmel. A partir de los componentes de la moda, observó las formas inestables (modificables) de las relaciones de poder y dinero entre los individuos y las instituciones. No el "objeto sociedad", sino "intercambio de efectos", estos pueden ser duraderos como los que se cristalizan en constituciones, iglesias y naciones; o pasajeros, como las modas, los usos y costumbres. En Digresión sobre el adorno explica que a medida que aumenta lo superfluo, aumenta la libertad e independencia de nuestro ser. Lo superfluo no impone ninguna ley de limitación, ninguna estructura. (SIMMEL, 1939, [1908], p. 360). 
Esto se articula con algunos aforismos de Honoré de Balzac: "El hombre acostumbrado al trabajo no puede comprender la vida elegante". (BALZAC, 2013 [1830], p. 11) y esto porque lo excepcional es aquel que tiene por trabajo la ociosidad, por ende, es "elegante y descuidado sucesivamente; se pone a su libre albedrío la bata del labriego o se decide por el frac llevado por el hombre a la moda; no está sometido a leyes, las impone" (BALZAC, 2013 [1830], p.11), condición sine qua non para ser moderno.

Tal como asevera Simmel en 1905 (en "Filosofía de la moda"): la moda implica un cambio social, específico, regular y no acumulativo (diferente a las ciencias) que se despliega en múltiples esferas de la vida social. En occidente, la moda será un fenómeno capaz de alterar los esquemas tradicionales. Es la comunicación de señales identitarias a través del atuendo, por ende, en el origen de la moda se encuentra la dinámica de la distinción y de la imitación.

A su vez habilita a que, el individuo, se reconcilie con lo colectivo al permitirle asentar sus gustos personales en un marco colectivo determinado. Es copia o imitación, que "no es más que aquello que de momento parece" para dar señales identitarias versus originalidad y diferenciación, tal como sucede con el vestido o el adorno que resultan algo por encima de la contingencia y de la persona (SIMMEL, 1939, [1908], p. 362).

Y como corolario a este intento de interrelacionar modaintelectuales, aclama Simmel: el imperio de la moda es más intolerable en aquellos órdenes donde sólo deben valer criterios sustanciales. La religiosidad, los intereses científicos, hasta el socialismo y el individualismo, han sido cuestión de moda. "Pero los motivos únicos que debieran influir en la adopción de estas posiciones vitales están en absoluta contradicción con la perfecta insustancialidad que 
gobierna el proceso de las modas" (SIMMEL, 2014 [1905], p. 39-40).

\section{ARTICULACIONES II: INTELECTUALES RIOPLATENSES Y SUS MODAS}

Yo no me ocupo sino de frivolidades, de cosas que a nadie van ni vienen, como son las modas, los estilos, los usos, una que otra vez las ideas, las letras, las costumbres (...).

Figarillo (Alberdi), "Mi nombre y mi plan", en La Moda. Gacetín semanal de música, poesía, de literatura, de costumbres. ( $\mathrm{N}^{\circ} 4$ - Buenos Aires Diciembre 9 de 1837)

Por una cuestión de economía del espacio, haremos un especial énfasis en el Río de la Plata, sobre todo en los Editores de La Moda. Gacetín semanal de música, de poesía, de literatura, de costumbres (contiene veintitrés números publicados que van del año 1837 a 1838. En adelante, La Moda). Fundado en la ciudad porteña de Buenos Aires, principalmente por Juan Bautista Alberdi.

Se supone que esta publicación pudo tener su fuente de inspiración en el semanario homónimo, mencionado anteriormente para el caso de Balzac. Si bien no hay apoyatura o pruebas materiales empíricas de una posible copia o imitación por parte de La Moda, de la francesa La Mode, creemos que fue Esteban Echeverría - quien estuvo en Francia entre 1826 y $1830^{8}$-, el que incitó e introdujo su lectura al propio Alberdi. En la mayoría de los artículos de La Moda se encuentran seudónimos o son anónimos ${ }^{9}$. Con el cierre de este gacetín porteño, debido a la censura del régimen de Rosas, muchos de ellos, se exiliaron en

\footnotetext{
${ }^{8}$ Cfr. GOLDWASER YANKELEVICH, 2009.

${ }^{9}$ Entre sus redactores, se contaba con Juan María Gutiérrez, Jacinto y Demetrio Peña, Vicente López y Carlos Tejedor, pero la pluma principal la llevaría el tucumano Alberdi. Este firmaba como "Figarillo", seudónimo que se debe a su admiración por quien fuera uno de los más importantes críticos de la España retardataria, Mariano José de Larra, cuyo seudónimo era "Fígaro". (Lojo, 2009: 13). Según la investigación de José A. Oria (1938), quien tuvo acceso a los distintos ejemplares en los que se atribuían los artículos, gracias a su trabajo comparativo puede suponerse con mayor precisión a quién pertenece cada uno, se sabe que, además de "Figarillo" (Alberdi mismo lo revela en el Gacetín); la inicial "E" se refiere a Demetrio Peña; "X" y "El regañón" a Vicente F. López; Los tres asteriscos (***) a Jacinto Peña; "Uno del Pueblo" y "Un abogado" a José Barros.
} 
Montevideo, y siguieron escribiendo sobre cuestiones y temáticas similares -e incluso repiten notas- pero en un periódico denominado El Iniciador ${ }^{10}$, publicado en la Banda Oriental entre 1838 y 1839.

En ambas publicaciones, los redactores pretendían incidir y actuar en la esfera pública, ofreciendo un material que modificara la dinámica social y la rutina de lectura del reducido público de la "buena sociedad porteña" (IGLESIA, ZUCCOTTI, 1997, p. 64)

En épocas del Salón Literario y, principalmente en el año 1837 se respiraba una relativa estabilidad política que le permitía pensar, por ejemplo, a Alberdi, en la posibilidad de diseñar un Estado como una república liberal y democrática. Desde aquella perspectiva, los jóvenes del 37 creían que la emancipación política, librada durante las guerras de la independencia no había sido acompañada por un movimiento cultural también emancipador (IGLESIA, ZUCCOTTI, 1997, p. 65).

El signo monárquico español de las costumbres coloniales siguió en pie y parecía permanecer en lo que fuera el régimen de Rosas en sus diferentes mandatos. Así es que La Moda vino a llenar un espacio para reformar o romper con las costumbres y hábitos añejos, en una ciudad ocupada por las novedades comerciales y políticas.

No obstante, esta Generación se desenvolvió, durante el régimen rosista, en un estado de "proscripción". Dado que fue un régimen que se basaba en el enfrentamiento, la censura de pensamiento, la persecución y la imposición de costumbres (BOTANA, 1997), muchos de los discursos de la Generación "desilusionada" del 37 fueron crípticos al intentar escapar a las reglas de la censura. Esto es así porque la disputa en el Río de la Plata se prolongó durante decenas de años alrededor de un tema clave: la oposición entre las

\footnotetext{
10 Según María Inés de Torres (1995), "la generación de El Iniciador" en la vecina orilla de la actual Uruguay, constituían un grupo involucrado en la lucha contra el despotismo que vivía el viejo continente pero que proyectaban, con legítima justificación, en el Río de la Plata.
} 
corrientes federales (con serios matices entre ellas, pero que los unificaba un ornamento llamado "divisa punzó" que clamaba "mueran los salvajes unitarios", "viva la Santa Federación") y los unitarios (La Moda titulará su tapa con un "Viva la Federación"). ${ }^{11}$

Observamos que, en el campo literario e intelectual hispanoamericano, esta temática sobre la moda aparece en obras clásicas de autores consagrados: Sarmiento, en su diario de Viajes por Europa, África y América de 1845; Bilbao con su "Sociabilidad chilena" y Bello en el poema "La Moda" (ambos publicados a mediados del siglo XIX en Santiago de Chile); Nieto Gil, en sus novelas Rosina (1842) o Ingermina (1844), autor perteneciente a la actual Colombia, entre otros. En algunos casos con una marcada influencia del pensamiento europeo; en otros, distanciándose de él.

"Con los experimentos liberales de comienzos del siglo XIX, las élites hispanoamericanas se vieron obligadas a redefinir sus vínculos con la tradición española y a actuar sobre la base de las nuevas realidades políticas" (GOLDGEL, 2013, p. 16; cursivas nuestras). De este modo, las costumbres y la tradición no iban de la mano. Las costumbres se convirtieron en una arena de lucha y transformación $^{12}$. Lo nuevo como imitación de algo ya existente en otro lugar, pero de lo que no se tiene experiencia, tuvo su espacio material en la moda, confundiéndose con el concepto "progreso". Y el periódico era la plataforma ideal para reflexionar acerca de las transformaciones culturales.

\footnotetext{
${ }^{11}$ Aquellos familiarizados con la historia argentina, encontrarán el marco bien conocido de enfrentamientos, exilios y debate. Y por economía del espacio, salteamos la época de 1826 - 1827, después de seis años de 'autonomías provinciales' cuando el Congreso General Constituyente reunido en 1824, para atender a la organización nacional, dictó una ley que establecía el cargo de "presidente de las Provincias Unidas", designando como capital a Buenos Aires. Entre 1827 y 1853 se diluye el gobierno nacional dando lugar a la denominada "Guerra Civil argentina" (1828-1831); Juan Manuel de Rosas, quien fuera gobernador de Buenos Aires en dos ocasiones: entre 1829 y 1832, y desde 1835 hasta 1852, con poderes extraordinarios sobre la provincia, asume también la representación de todas las demás frente a los países extranjeros. Había un federalismo de hecho.

12 "Durante la primera mitad del siglo XIX la novedad desempeñó un papel central tanto en los esfuerzos por fundamentar la legitimidad política de las naciones hispanoamericanas como en la reformulación del vínculo que los sujetos establecían con el tiempo y con la historia". (GOLDGEL, 2013, p. 24).
} 
Nos interrogamos cómo interpretar "la historia en carne y hueso" a partir de las diferentes novedades introducidas en América hispana a través de los escritos literarios como jurídico-políticos; ¿qué desenvolvimientos y efectos ellas produjeron en nuestras sociedades políticas? $\mathrm{Y}$, por último, ¿cómo los intelectuales del Río de la Plata habrán pensado el "ser moderno" en tiempos de construcción de la identidad nacional, en particular aquellos que se han dedicado a escribir en La Moda, tal es el caso del "padre" de la futura Constitución nacional, Juan Bautista Alberdi?

Demás está decir que en la Constitución de la Confederación Argentina que se promulga en 1853 queda "explícita" la exclusión de la mujer como sujeto de derechos políticos. Sin embargo, en los escritos de los hombres de mediados del siglo XIX, considerados forjadores de la nación argentina, aparecen huellas de la transición de la mujer de objeto (del otro) a sujeto de derechos.

La mujer no siempre fue escrita 'negativamente', sino que ha sido incluida en un campo de fuerzas donde los sentidos disputaban entre sí. Por eso decimos que, en los escritos sobre moda, aparecen contradictorias figuraciones de la mujer, escritas por hombres del siglo XIX preocupados por salir de la dominación hispánica, sin por eso ingresar a un salvajismo autóctono.

Según GOLDGEL, el proceso de emancipación política del Río de la Plata se asocia con el surgimiento de un nuevo medio (el periódico), la consolidación de un dispositivo social que opera una renovación constante de objetos y prácticas (la moda) y la continuidad entre dos formaciones discursivas del periodo (la Ilustración y el Romanticismo). Afirma que estos tres elementos se legitimaron sobre el soporte de lo novedoso, siendo "lo nuevo" el objeto de reflexión permanente en la época de la naciente era republicana.

En la producción literario-periodística de la Argentina decimonónica, la alusión a las modas extranjeras - 
principalmente europeas- como parte del proyecto nacional puede ser vista como una forma alternativa de propaganda nacionalista (HALLSTEAD, 2004, p. 54). Algo similar sostiene Regina ROOT (2014) al aseverar que la moda ocupó un campo de batalla de significantes, en particular a los jóvenes patriotas les permitió distanciarse de las reliquias del colonialismo español.

Una de nuestras hipótesis que hemos investigado ${ }^{13}$, sostiene que cuando se pone la atención en el romanticismo político se olvida la función de la mujer escrita, y cuando se recuerda la función de la mujer se desatiende el contexto político de aquella corriente.

Si insistían en la ropa femenina era porque la mujer debía desempeñar un rol cardinal como reproductora de las costumbres democráticas en el seno de la familia, pero "la igualdad de derechos no remitía a ella sino al sector masculino adulto" (MOLINA, 2005, p. 160). Creemos que aquella invocación problematiza la noción de igualdad (política) y que ese conflicto se vislumbra precisamente a través del papel que ejerció la moda en esos discursos.

Aquella insistencia se puede corroborar en las dos publicaciones más prominentes sobre la temática de esta juventud romántica argentina de la Generación del '37 como lo fueron: La moda y el periódico quincenal El Iniciador.

Resulta pertinente la pregunta de por qué siendo la moda, como así también la figura mujer tan relevantes para algunos de los miembros del '37, algunos estudios historiográficos -clásicos o contemporáneos- han suprimido sus análisis. ¿Por qué son desatendidas, mientras que la figura del extranjero, del inmigrante, del gaucho, el indio, la frontera, el desierto, la barbarie, el héroe, el caudillo son herramientas analíticas para comprender una propuesta política de la época y circunscribir el concepto de nación? ¿Qué hay detrás de esta omisión? ¿Hay una decisión

${ }^{13}$ Ampliamente desarrollada en GOLDWASER YANKELEVICH, 2012. 
metodológica de dejarlas de lado o bien una partición de campos entre "teorías feministas", "sociología de la moda" e "historia política"?

Emerge la sospecha de que esta supresión se debe a que en la imaginaria división de campos de estudio, todo lo que se relacione a la temática "mujer" (tanto como sujeto o como objeto de discurso) debe -ineludiblemente- ser abordada por la teoría feminista y las corrientes comúnmente encargadas al "género" (femenino) o de la vida cotidiana; mientras que el hecho explícito de la exclusión de la mujer en el ámbito de la política no permite entrever que, de todas formas, su figura contribuyó a la construcción de los conceptos aquí en cuestión. Muchas veces, los mismos historiadores restan importancia a esta figura, no siempre de manera explícita o intencional.

Por ello, una mirada atenta sobre los textos nos ha permitido aislar cuatro posiciones centrales que son modos de aparición de la mujer bajo la pluma de los hombres forjadores de la nación.

Estas posiciones o figuras entonces contribuirán a una lectura de las fuentes decimonónicas, interpretarlas e incluso sistematizar los estudios contemporáneos que se han dedicado a aquel siglo. Además, reducen los modos de aparición de ella bajo la pluma de los hombres que reflexionaron sobre la idea de moda, la nación y su constitución política, a saber:

I) La figura de la mujer cual objeto de (la) ilustración, es decir, esos paréntesis indican que, ora como destinataria predilecta, ideal de un público que debe ilustrarse y atender las producciones discursivas de los hombres románticos; ora como "mujer objeto" que ejemplificaría un ideal: el de un receptor que escucha, lee pero no decide ni critica, un "maniquí", el componente primordial del orden social, útil para el acatamiento de la política doctrinaria de la época que es la que, al fin y al cabo, abre paso discursivamente a la 
legitimidad de un Estado. Institución que debe controlar el caos de la sociedad civil donde subsiste aún la barbarie.

Señalamos un ejemplo: en La Moda, cuando sus redactores se interrogan sobre quién debe ocuparse de la misión y la condición social de la mujer, la respuesta es que depende de la nueva generación "inteligente y ávida de conocimientos" ya que eso es ocuparse del devenir de una nación. (La Moda, No 19, 24/3/1838: 6).

II) La que refiere a ella como un pretexto (o excusa), herramienta (arma) discursiva para poder apelar a cuestiones de otro tenor, sobre todo en tiempos de censura a la libertad de expresión. Muchas veces, tanto la mujer como el concepto moda funcionaron como pretexto, pero también como potencia, dentro del discurso, para propugnar o impulsar un cambio en lo tocante, no sólo a la cultura, sino también a la política. Siguiendo el ejemplo anterior, en el mismo Gacetín, para criticar al pueblo -actual soberano-, se refieren a "las mugeres" (sic), como "entes anónimos", sin individualidad, por ende, sin una responsabilidad real: Ellas "todo lo pueden y lo saben, porque son muchas: en la muchedumbre está la omnipotencia y la infalibilidad. La muchedumbre es la ignorancia: la ignorancia es su título de soberanía". (sic, La Moda, No 18, 17/3/1838: 5).

III) La intrusa ${ }^{14}$, un obstáculo para el progreso. Una figura que rompería con la fraternidad y armonía entre los iguales, los hombres. La intrusa es encarnada en la figura de la mujer, muchas veces para manifestar la extrañeza que genera lo 'viejo', lo que no encaja en la doctrina o plan que se tiene proyectado. Tal es el caso de la figura limeña de "la tapada" en los relatos de viaje de Sarmiento. Este anota que, merced a un traje que los españoles adoptaron de los árabes por espíritu religioso, cuando las mujeres no visten a la europea, solteras o casadas -nos aclara el autor-, se

\footnotetext{
14 Tercera posición inspirada en el cuento homónimo de Jorge Luis Borges (1974), incluido en El informe de
} Brodie. 
colocan una saya, cubren su cabeza y rostro con el manto, "dejando descubierto apenas un ojo travieso y burlón, y desde ese momento todos los vínculos sociales se aflojan para ellas, si no se desatan del todo" logrando "ser libres como las aves del cielo". (SARMIENTO, 1848, p. 9)

IV) Por último, si en el texto decimonónico se reflexiona sobre la mujer cual "sujeto activo", de manera explícita, esto es, qué hacer para adaptarla a los nuevos tiempos venideros, entonces lo que emerge es una figura de la frontera, bisagra que iluminaría el paso de una época antigua (la colonia), a una moderna (el Estado - nación o la fundación de la República, según el caso). Una figura que obliga a proyectar un futuro mediato, diferente al actual. Ya no como pretexto, ya no como objeto, sino como un momento de conciencia que percibe el cambio político y cultural, de esclarecimiento en torno a la situación contemporánea. Esta figura (en relación a las otras tres) implica la comparación, igual que sucede con la moda: apela a un antes y a un después, y sólo puede ser mencionada por quienes poseen un pensamiento progresista de la historia de un pueblo, de una patria o de la nación. En definitiva, una figura que remite a la subjetividad de la transición.

Los Editores de La Moda tenían claro tres caracterizaciones (sin jerarquías en su mención) acerca de la condición femenina:

$\left.1^{\circ}\right)$ La mujer dependiente de la frivolidad, la coquetería, el ornamento y el matrimonio;

$2^{\circ}$ ) La absolutamente libre y fuera de control, "la mujer" (de la calle) en contraposición a "La Señora y la señorita"; y

$3^{\circ}$ ) La víctima de una sociedad (o de la mitad de ella).

La resolución, para Alberdi, sería una familia que la contenga siempre y cuando no le quite la libertad de acción en el mundo público, mientras que la presión de la sociedad debería llevarlas a comprender que depende de ella proteger 
su autonomía, pero que se ajuste a las necesidades de su nación.

¿Quién debe hacerse cargo, de quién es la culpa? Los editores no dudan en afirmarlo: "el hombre pone el último sello a los defectos de su educación, haciéndola vana, coqueta, falsa", la mujer es preparada "para la dicha del padre, del esposo, del hijo", y eso sólo ofrece ilusiones que desaparecen como el sueño o como la moda. Aquí, la mujer es una víctima, pero al ser una condición es, desde luego, temporal, pasajera. Escriben: "su principal condición es agradar, el lujo la deslumbra, un tocador absorbe sus preciosas horas, (...) ojea rápidamente una insignificante novela". (sic, La Moda, No 19, 24/3/1838: 6).

Entonces, si tal como se ha registrado hasta aquí, el cambio en las costumbres -que debe comenzar por suplantar un tipo de familia argentina por otro, escribe Alberdi y Los Editores- pende de la mujer. ¿De qué dependió su condición? Dos artículos en La Moda, pero que se deben leer como uno solo, arrojan algunas concepciones más. Ambos bajo el subtítulo "Al Bello Sexo". Uno aparecido en el No 5; el otro (que se supone es una aclaración de este), cuatro números más tarde. Nos permitimos citar al primero casi en toda su extensión por lo revelador de su mensaje y lo avanzado en su pensamiento:

Cuando toda la humanidad progresa, cuando la precoz y ardiente juventud argentina recibe con una celeridad eléctrica, las ideas, el progreso del siglo ¿habrá de permanecer la muger estacionaria? La dulce compañera del hombre, esa alma con que se ha de unir la suya en un lazo eterno de felicidad ¿continuará siempre tan distante, tan inferior a él? No: la muger está destinada a llegar en este siglo de nivelación a su verdadera condición social. La tarea es grande y noble, y lo que es mas, su mejor éxito pende de la muger misma. Apresúrese pues, el bello sexo argentino a desencadenarse de la frivolidad, de las preocupaciones de una educación añeja y viciosa, abandone la ociosidad mental (...). 
(...) Deje de considerar el saber ajeno de ella -la instrucción es el verdadero camino de la virtud, (...) De otro modo nunca saldrá de la esfera de un artículo de lujo, de una administradora doméstica, de una compañera momentánea de entretenimiento y de placer a los sentidos; rol degradante (...) (La Moda, N05, 16/12/1837: 3; cursivas nuestras).

En este primer largo párrafo, el autor presenta a la figura de la mujer como un sujeto capaz de liberarse por sí misma. Es una figura de la transformación, debe modificar su condición que hace que ocupe un lugar superficial. Además, se ilumina una respuesta posible: hubo una educación añeja y viciosa. Por ello, ubicamos aquí la figurafrontera en la que el autor avizora la necesidad de un cambio, de un progreso entendido en términos de modernización, frente a lo viejo -que en este caso es la educación recibida- de entonces.

Esta figura es, si se quiere, un caso - ejemplo. A la vez que interpela a la figura de la mujer, apela a toda la sociedad.

La autoconciencia de los Editores de la situación de la mujer es significativa. Es el propio Alberdi quien está detrás de todo ello:

La obra Bases (ver nota al pie 1) es posterior a La Moda. De la lectura de Bases se podría afirmar que, para Alberdi, la mujer debía estar excluida de la política. Sin embargo, la articulación Bases - La Moda, ilumina una postura intersticial entre la mujer "verdadera y la posible"15. Ve como utópica la posibilidad que las constituciones de Hispanoamérica puedan realizar la república representativa y esto por querer copiar "los ensayos filosóficos que la Francia de 1789 no pudo realizar" (ALBERDI, 1981 [1852], 1981, 233). Recordemos que cuando se copia una moda política deja de ser una novedad y pasa a ser un injerto difícil de llevar adelante. Para Alberdi, si bien se puede empezar por

\footnotetext{
15 Parafraseando al Capítulo XII de Bases: "Falsa posición de las repúblicas hispanoamericanas. La monarquía no es el medio de salir de ella, sino la república posible antes de la república verdadera".
} 
redactar una constitución, lo que verdaderamente se necesita es

(...) suplantar nuestra actual familia argentina por otra igualmente argentina, pero más capaz de libertad, de riqueza y progreso (...) La América del Sur posee un ejército a este fin, y es el encanto que sus hermosas y amables mujeres recibieron en su origen mejorado por el cielo espléndido del Nuevo Mundo. Removed los impedimentos inmorales que hacen estéril el poder del bello sexo americano y tendréis realizado el camino de nuestra raza, sin la pérdida del idioma ni del tipo nacional primitivo. (ALBERDI, 1981 [1852], 1981, 233234; destacado nuestro).

La mujer escrita por Alberdi es la bisagra entre el tipo criollo y el nuevo tipo 'americano' producto de la fusión de las 'hermosas y amables mujeres' del Nuevo Mundo; y la eliminación de la herencia colonial que hizo "estéril el poder del bello sexo americano". La nueva familia argentina tendrá en el ideario alberdiano, la potencia del hombre europeo con el resguardo de la tradición idiomática y el tipo físico (depositado en las mujeres). Pero mientras no estén dadas las condiciones para que "lo ideal" se realice, entonces se debe pensar en lo posible. $Y$ lo posible el jurista lo encuentra, respecto a la figura de la mujer, en el siguiente párrafo:

En cuanto a la mujer, artífice modesto y poderoso, que desde su rincón hace las costumbres privadas y públicas, organiza la familia, prepara el ciudadano, echa las bases del Estado, su instrucción no debe ser brillante. No debe consistir en talentos de ornato y lujo exterior, como la música, el baile, la pintura, según ha sucedido hasta aquí. Necesitamos señoras y no artistas. La mujer debe brillar con el brillo del honor, de la dignidad, de la modestia de su vida. Sus destinos son serios; no ha venido al mundo para ornar el salón sino para hermosear la soledad fecunda del hogar. Darle apego a su casa, es salvarla; y para que la casa la atraiga, se debe hacer de ella un edén. (...) una mujer laboriosa no tiene tiempo de perderse ni el gusto de disiparse en vanas reuniones. Mientras la mujer viva en la calle y en medio de las provocaciones recogiendo aplausos, como actriz, en el salón rozándose como un diputado entre esa especie de público que se llama la sociedad, educará a sus hijos a su imagen, servirá a la República como Lola Montes, y será útil para sí misma 
y para su marido como una Mesalina más o menos decente. (Alberdi, 1981 [1852], 1981, 79 -80; cursivas nuestras).

Hay que analizar detenidamente. En general, cuando se menciona este pasaje se lo suele recortar. Por ejemplo, BATTICUORE afirma que "Alberdi expresa en una suerte de fórmula drástica el destino de la instrucción femenina", y solamente cita "Queremos señoras y no artistas" (BATTICUORE, 2005: 49). Lo mismo sucede en el prólogo de María Rosa LOJO (2009: 16). Para LOJO, esta frase evidenciaría un pensamiento sexista en Alberdi.

Es de fundamental importancia retomar todo el párrafo ("hacerle justicia") y contextualizarlo según las ideas del autor. Esto porque aquí precisamente acontece el papel político que Alberdi le asignaría a la figura de la mujer y a la moda en el escenario fundacional de la nación por venir.

Cuando se refiere al tipo de instrucción de la mujer, agrega que esta "no debe ser brillante". (BATTICUORE, 2005, p. 36). Es preciso advertir y aclarar que "brillante" connota un rasgo negativo (como la brillantez de la luna cuya luz no es propia) porque refiere al mundo del ornamento y de la vida "superficial", es decir, al espacio público de su tiempo compuesta por una sociedad que Alberdi observa y desdeña.

Entonces "darle apego al hogar" es "protegerla" de la corrupción que pueda sufrir por culpa de la sociedad aún colonial. La mujer tiene un poder único que hay que preservar: hacer las costumbres privadas y públicas, echar las bases del Estado, ni más ni menos. Según el tucumano, es una tarea seria. Por ello contrapone dos figuras de "mujeres desviadas" o "mujeres intrusas": Lola Montes y Mesalina. El motivo de fondo o la causa pareciera ser el modo en que la sociedad corrompe y coloca en un lugar superficial a las mujeres.

¿Es hoy imaginable que, en la primera mitad del siglo XIX, un hombre o un grupo de hombres intelectuales, 
ubicados en un espacio de visibilidad -como lo era la prensa gráfica-, denunciaran este tipo de "desvíos", corrupción del cuerpo y el hacer femenino? Los estudios contemporáneos no han dado cuenta del ejercicio de autorresponsabilidad que ha hecho esta generación respecto a la situación de las mujeres.

Por ende, la mujer escrita adoptó diferentes anatomías imaginarias (MATHIEU, 1991). En este punto surge la pregunta: estas figuras rastreadas en los escritos sobre moda, ¿nos permitirían comprender, a través de expresiones singulares las concepciones epocales?

La identidad del intelectual hispanoamericano puede ser expresada en una pregunta alberdiana: ¿cómo escribir con una lengua que no es la propia?, ¿cómo construir una cultura con elementos heredados de la colonización o del mundo europeo? Se le plantea así el gran tema de la 'dependencia' o de los distintos 'espejos' en los que contemplarse como constitutivo de la problemática latinoamericana, convertido en un tópico obsesivo, y por eso el concepto "moda" colabora tanto con sus ideas intelectuales. En otras palabras, se trata de la anomalía de una modernización sin sujetos modernos.

\section{CONCLUSIONES}

Soy hijo de español, y ya se sabe que todo hijo de español no debe hacer toda su vida sino lo que hizo su padre: no debe ser mas que una imitación, una copia, una tradición de su padre, es decir, siempre imitación, siempre copia, siempre rutina, como v. g. nuestra patria, de su madre patria. (...)

"Figarillo (Alberdi), "Mi nombre y mi plan" (continuación), en La Moda. Gacetín semanal de música, poesía, de literatura, de costumbres. ( $N^{\circ} 5$ Buenos Aires Diciembre 23 de 1837).

Lo que quisimos mostrar hasta aquí es, por un lado, la postura ambivalente que ciertos intelectuales adoptaron respecto al concepto moda; en segundo lugar, exponer que 
al referirse a ella, indefectiblemente refieren a la diferencia de los sexos, al hombre y/o a la mujer, según el caso.

En tercer lugar, y a pesar de las influencias de la Europa no española, algunos intelectuales hispanoparlantes han diagnosticado un destino para su patria o nación a partir de nuevos modos de entender la moda.

En todo caso, anotamos la politización del concepto y su intrínseca relación con la historia del pensamiento y la literatura en ciertos hombres intelectuales del siglo XIX.

Tal como diagnosticó George Simmel en 1905 (uno de los autores que abordamos en el apartado segundo), la cuestión de la moda no es ser o no ser, sino que ella es simultáneamente ser y no ser, se sitúa siempre en aquel parteaguas entre el pasado y el futuro, proporcionando así, durante su apogeo, un sentimiento de presente tan intenso como su propia muerte.

El dualismo que pretendimos demostrar se hizo "carne y hueso": Honoré de Balzac, Baudelaire, Simmel, Benjamin; Sarmiento, Alberdi y la Generación del 37 del Río de la Plata han demostrado cómo han conquistado el concepto moda y su clara reminiscencia con la construcción socio-política de su tiempo. Sus obras, por cierto, construyen lo que podemos denominar "cultura material" en momentos de reflexionar sobre la modernidad.

Parafraseando el diagnóstico alberdiano de una modernidad sin sujetos modernos puede saldarse con un re-pensar el concepto moda en nuestras latitudes. Volver a reflexionar en un "ser latinoamericano" en momentos en el que el "no ser globalizante" se impone, es un desafío que merece un estudio ulterior.

\section{REFERÊNCIAS}


ALBERDI, Juan Bautista. Bases y puntos de partida para la organización política de la República Argentina, Buenos Aires: Plus Ultra. 1981 [1852].

ALEMANY Y BOLUFER, José (Dir.). Diccionario Enciclopédico Ilustrado de la Lengua Española. Buenos Aires: Editorial Ramón Sopena. 1945.

ALTAMIRANO, Carlos. Para un programa de historia intelectual $y$ otros ensayos. Buenos Aires: Siglo veintiuno. 2005 .

ANSALDI, Waldo, Verónica GIORDANO. La construcción del orden, Tomo I. Buenos Aires: Ariel. 2012.

ARON, Raymond. El opio de los intelectuales. Buenos Aires: Ediciones siglo veinte. (1967) [1955].

BARD, Christine. Historia política del pantalón, Buenos Aires: Tusquets. 2012.

BATTTICUORE, Graciela. La mujer romántica: Lectoras autoras y escritores en la Argentina: 1830 -1870. Buenos Aires: Edhasa. 2005.

BAUDELAIRE, Charles. El pintor de la vida moderna. Buenos Aires: Taurus. 2014 [1863].

BENJAMIN, Walter. "Moda". En Libro de los pasajes. Madrid: Akal. 2005.

BERNARLDO DE QUIRÓS, Pilar. Civilidad y política en los orígenes de la nación argentina. Las sociabilidades en Buenos Aires. 1829-1862. Buenos Aires: Fondo de Cultura Económica. 2008

BORGES, Jorge Luis. "La intrusa", en Obras Completas. Buenos Aires: Emecé. 1974.

BOTANA, Natalio. La tradición republicana. Buenos Aires: Editorial Sudamericana. 1984.

DE BALZAC, Honoré. Tratado de la vida elegante, IbnKhaldun, 1830. Disponible en https://librosgratis.com/ebooks/tratado-de-la-vida-elegante-honore-debalzac/

DE TORRES, María Inés. ¿La nación tiene cara de mujer?: Mujeres y nación en el imaginario letrado del siglo XIX. Montevideo: Arca. 1995.

GODOY DOMÍNGUEZ, Ma. Jesús. "El pintor de la vida moderna, de Charles Baudelaire". En Fedro. Revista de Estética y Teoría de las Artes, $N^{\circ} 7$, septiembre, p. 3-25. 2008.

GOLDGEL, Víctor. Cuando lo nuevo conquistó América. Prensa, moda y literatura en el siglo XIX, Buenos Aires: Siglo XXI. 2013. 
GOLDWASER YANKELEVICH, Nathalie. "Amistad, locura y Utopía. Notas sobre la obra de Tomás Moro", en Forster, R., (comp.) Utopía. Raíces y Voces de una tradición extraviada, Buenos Aires: Altamira. P.39-58. 2008.

GOLDWASER YANKELEVICH, Nathalie. "Esteban Echeverría en París (1826-1830) ¿Una incógnita histórica?", en Vermeren P. y M. Muñoz (comps.), Repensando el siglo XIX desde América Latina y Francia. Homenaje al filósofo Arturo A. Roig, Buenos Aires: Colihue, p. 277-290, 2009.

GOLDWASER YANKELEVICH, Nathalie, Figuras de la mujer en los proyectos nacionales. Literatura y política en el Río de la Plata y Nueva Granada (1835-1853), Tesis Doctoral (inédita) defendida en la Universidad de Buenos Aires y en la Universidad de Paris 1 Panthéon Sorbonne, Buenos Aires - París, 2012.

HALLSTEAD, Susan. "Políticas vestimentarias sarmientinas: tempranos ensayos sobre la moda y el buen vestir nacional", en Revista Iberoamericana, 70(206), p. 53-69. 2004. Disponible en https://revista-iberoamericana.pitt.edu

IGLESIA, Cristina y Liliana ZUCCOTTI. "El estilo democrático: último grito de la moda". En Mora. Revista del Área Interdisciplinaria de Estudios de la Mujer, Buenos Aires: Facultad de Filosofía y Letras, Universidad de Buenos Aires AIEM, pp. 64-73. 1997.

INICIADOR, EL. Reproducción facsimilar, Academia Nacional de la Historia, Buenos Aires: Guillermo Kraft. [15 de abril de 1838 a 1 de enero de 1839, Montevideo]. 1941.

LOJO, María Rosa. "Alberdi, el paradójico", en El pensamiento de Juan Bautista Alberdi. Buenos Aires: Ed. El Ateneo, pp. 9-22. 2009.

MATHIEU, Nicole-Claude. L'anatomie politique. Catégorisations et idéologies du sexe. Paris : côtéfemmes. 1991.

MODA, LA: Gacetín semanal de música, de poesía, de literatura, de costumbres. Buenos Aires: Academia Nacional de la Historia. [1837-1838], 1938.

MOLINA, Eugenia, "Civilizar la sociabilidad en los proyectos editoriales. Del grupo romántico al comienzo de su trayectoria (1837 - 1839)", en Batticuore, G., K. Gallo y J. Myers (comps.), Resonancias Románticas. Ensayos sobre historia de la cultura argentina (1820 - 1890). Buenos Aires: Eudeba, pp. 151-166. 2005.

MORO, Tomás. Utopía. Madrid: Alianza Editorial. 2008 [1516]

ROMANO SUED, Susana. Dilemas de la traducción.

Políticas. Poéticas. Críticas. México: UNAM. 2016. 
ROOT, Regina. Vestir la nación. Moda y política en la Argentina poscolonial. Buenos Aires: Edhasa. 2014.

SAULQUIN, Susana. La moda en la Argentina. Buenos Aires: Emecé. 1990.

SAPIRO, Gisèle. Los intelectuales: profesionalización, politización, internacionalización. Villa María: EDUVIM. 2017.

SARMIENTO, Domingo F. Discurso presentado para su recepción en el Instituto Histórico de Francia. 1848. Recuperado de http://www.proyectosarmiento.com.ar.

SIMMEL, Georg, "Digresión sobre el adorno". En Sociología. Estudios sobre las formas de socialización. Buenos Aires: Espasa Calpe. Pp. 358-364. 1939 [1908].

SIMMEL, Georg, Filosofía de la moda. Madrid: Casimiro. 2014 [1905].

REAL ACADEMIA ESPAÑOLA. Disponible en http://www.rae.es/.

TRÉSOR DE LA LENGUE FRANCAISE INFORMATISÉ. Disponible en http://atilf.atilf.fr/

WEBER, Max. Ensayos sobre Sociología de la Religión, Tomo I, Taurus: Madrid. (1987) [1917-1919]

ZAMBRINI, Laura. "Prácticas del vestir y cambio social. La moda como discurso". En Revista Questions, Nro. 23. Buenos Aires: Facultad de Periodismo y Comunicación Social de la Universidad de La Plata. 2009. 